\section{MALARIA IN NEIGHBOURING LONDONERS}

BY

\section{G. S. CROCKETT, M.D., M.R.C.P.} Senior Medical Registrar, Lambeth Hospital AND

\author{
K. SIMPSON, M.D., M.R.C.P. \\ Registrar to the Children's Department, St. Thomas's \\ Hospital
}

Although cases of primary malaria in England have been recorded from time to time (British Medical Journal, 1950), including several arising in London (Fermont, 1947; Blaxland Levick and MacGregor, 1947), the occurrence of malaria in neighbours, within a few weeks of one another, seemed unusual enough to warrant an account.

\section{Case 1}

A housewife aged 27 was admitted to Lambeth Hospital, under the care of Dr. A. A. Guild, on August 7, 1953, complaining of fever and headache. She noticed that her fever came on alternate days.

In May, 1953, she had had a febrile illness at home which was thought to be pneumonia, but chest radiographs taken at that time showed no definite abnormality. The illness had lasted five weeks, and the temperature then had not shown the periodicity which was a feature of her present illness. In August, 1952, the patient had visited Nice, and, with her husband, made trips into the surrounding country.

On examination the spleen was enlarged 3 in. $(7.5 \mathrm{~cm}$.) below the costal margin and her temperature rose on alternate days to $104.2^{\circ} \mathrm{F}$. $\left(40.1^{\circ} \mathrm{C}\right.$. $)$. The blood films showed fairly numerous parasites of $P$. vivax, including gametocytes. She was treated with mepacrine, $200 \mathrm{mg}$. eighthourly for 48 hours and then $100 \mathrm{mg}$. eight-hourly for 24 hours, followed by primaquine, $10 \mathrm{mg}$. daily for 14 days.

As her peripheral blood contained gametocytes and her fever was of the classical tertian type it was thought that this was not her first attack and that her illness the previous May was probably the primary attack.

\section{Case 2}

A boy aged 8 years was admitted to the Royal Waterloo Hospital under the care of Dr. B. D. R. Wilson on June 30 , 1953. He had been referred for the investigation of attacks of shivering with splenomegaly. Until one month before admission he had been perfectly well. He then began to have recurrent feverish attacks. These started suddenly with malaise, followed by a feeling of coldness and shivering. After about three hours he started sweating and became flushed. In another three hours the episode was over. The attacks occurred on alternate days, and in between each attack he felt quite well. There was no history of any febrile illness in the preceding two years. The patient had lived in London since the age of 2 , and his most recent trip was to the Isle of Sheppey in 1951.

$\mathrm{He}$ had an irregularly remittent pyrexia during his first four days in hospital, ranging from $99^{\circ}$ to $101^{\circ} \mathrm{F}$. (37.2 to $38.3^{\circ}$ C. $)$. His spleen was enlarged about 2 in. $(5 \mathrm{~cm}$.) below the costal margin. Parasites of benign tertian malaria were found in the blood.

The boy was treated with chloroquine, $0.45 \mathrm{~g}$. stat., $0.3 \mathrm{~g}$. twice daily for three days, followed by pamaquin, $5 \mathrm{mg}$. three times a day for 12 cays. His fever did not recur after the start of the treatment, and his spleen diminished in size until only the tip was palpable, when he was discharged (August 8).

This was thought to be a primary malarial attack.

\section{Discussion}

These two patients live in adjacent semi-detached houses in Stockwell (South London). Each house has a small garden containing several poorly lit sheds and patches of thick undergrowth. In one garden there was a large pigeon loft and an enclosure containing a dog, while in the other there was a discarded tank half full of stagnant water. No mosquitoes or larvae were found in the houses or gardens when we visited them in August, 1953, but on waste ground near by numerous mosquitoes were captured among some sprouting tree-stumps. These, disappointingly, proved to be culicines.

The possible modes of infection in these two cases were : (1) The first patient contracted malaria during her visit to Nice, and this was transmitted during May to the boy. Against this may be set the fact that malaria is not endemic in the Nice area (P. G. Shute, personal communication). (2) Both cases contracted malaria in Stockwell from a third person recently returned from a malarious area. No such person was known to be living in the vicinity. This, of course, does not rule out the possibility. (3) Each case acquired malaria independently elsewhere. Neither case had ever received a blood transfusion or injection. Inquiries into the possibility of malarious mosquitoes, used for therapeutic purposes, having been released in the neighbourhood produced negative results. The boy had not been out of London for two years.

Since the third possibility seems too much of a coincidence, it must be assumed that transmission was via local anopheline mosquitoes.

The following three species may be found in London: A. maculipennis, the most widespread anopheline in this country, will breed only in natural collections of water, of which there are none locally. Moreover, the variety atroparvus, the one most likely to transmit malaria in Britain, breeds in coastal salt waters (Marshall, 1938a). A. claviger, however, will breed in tanks (Marshall, 1938b). A. plumbeus, a tree-breeding type, has been shown experimentally to carry malaria, and is common in London (H. I. Leeson, personal communication).

Either $A$. claviger or $A$. plumbeus was the likely vector in these cases, and the fact that they were not caught locally in August does not rule out their presence there during the previous May.

We should like to acknowledge the help received from Major H. I. Leeson, of the London School of Hygiene and Tropical Medicine, and from Mr. P. G. Shute, of the Malaria Reference Laboratory, Horton. We are grateful to Dr. B. D. R. Wilson and Dr. A. A. Guild for permission to record these cases.

\section{REFERENCES}

British Medical Journal, 1950, 1, 1061

Fermont, D. A. (1947). British Medical Journal, 2, 31

Levick, C. B., and MacGregor, M. E. (1947). Ib:d., 1, 764 Marshall. J. F. (1938a). The British Mosquitoes (published by order of the British Museum), p. 118

(1938b). Ib:d., p. 129.

Professor Frederick Heaf, David Davies Professor of Tuberculosis at the University of Wales, left London by air on November 15 for Turkey, where he is to lecture, under British Council auspices, on tuberculosis and discuss preventive measures with Turkish specialists in Ankara and Istanbul. His visit is at the request of the Turkish Ministry of Health, and he will be there for three weeks. He is then to visit Greece from December 6 to 12, and will lecture to medical societies in Athens and Salonika. In Istanbul he will lecture to a congress of doctors, arranged by the World Health Organization, which begins in the first week of December. Medical men from 16 countries will attend, and the Congress includes special courses on tuberculosis. Professor Heaf's lectures will include the prevention, diagnosis, and treatment of tuberculosis, and anti-tuberculosis vaccination. In Turkey and Greece, British films on tuberculosis will be shown in connexion with the lectures. 